PROCEEDINGS: THE SOCIETY OF SPORTS SCIENCE

Loughborough University. 23rd September, 1977

\title{
A SURVEY OF DISORIENTATION AND OTHER PROBLEMS AMONG CANOEISTS FOLLOWING IMMERSION IN COLD WATER
}

\section{S. J. BAKER \\ Bangor Normal College of Education}

As an initial step to a broader study of the disorienting effects of cold water immersions on top class competitive canoeists a survey was made of the incidence of hazardous immersions amongst a majority sample of the better canoeists in the country. Virtually the entire entry to one of the most important national competitive meets was canvassed. A total of 288 canoeists in the 1st and 2nd divisions were identified and asked to participate. Replies were received from 247 (86\%). All those responding had had extensive experience of canoeing in winter spate and were capable of fast and efficient first-time canoe rolls in cases of capsize. Particular interest was focussed on the $85(29 \%)$ who had had at least one experience of capsizing in very cold water (about $8^{\circ} \mathrm{C}$ ) during training or competition in mid-winter.

Most respondents viewed the winter capsize seriously. Despite their familiarity with the conditions in which they trained about nine out of ten $(86 \%)$, recalling their

\section{J. ATHA}

\section{Loughborough University of Technology}

capsize experiences, reported they had felt at least some concern, and two out of ten (21\%) experienced extreme alarm, when it happened.

A number of marked physical symptoms that regularly attended on a capsize were widely reported, the most usual of which was severe pain in the forehead $(89 \%)$ and breathing and speaking difficulties $(64 \%)$. Additionally $62 \%$ reported sensory problems including visual difficulties, dizziness and disorientation. Five canoeists admitted fainting. Despite these hazards few appeared to take preventive measures, and clothing with negligible clo values was the rule rather than the exception, for instance $80 \%$ wore nylon anoraks. It is concluded that transient cold immersions produce disorienting and other disturbing effects of which the canoeist, though aware, and probably to his own disadvantage, takes little notice. The disorientation effects reported were discussed and some of the possible mechanisms mediating them considered.

\section{MEASUREMENT OF OXYGEN CONSUMPTION - RECENT DEVELOPMENTS \\ D. A. BRODIE* , S. HUMPHREY†, D. LAYMANT†, A. E. de LOOY** \\ ${ }^{*}$ Carnegie School of Physical Education and Human Movement Studies, Leeds Polytechnic \\ tBioengineering Division, Clinical Research Centre, Northwick Park, Harrow \\ t+Chelsea College, University of London \\ * *School of Health and Applied Scierices, Leeds Polytechnic}

Two methods of measuring oxygen consumption were described. The first method offers the continuous display of expiratory volume and oxygen percentage on two channels of an inexpensive pen recording system. A coupler was designed to process the electrical output from a Wright flow meter (BOC, Ltd.) so that inspiratory volume for each breath was displayed and for the pen to re-set to zero after each 5 litres. The other coupler continuously monitored the expired air and displayed the oxygen percentage on the second oscillograph channel. This method, although still in the prototype stage, is expected to be far less expensive (estimated cost approximately $\mathrm{f300}$ ) than the alternative procedures. It has the additional advantage of presenting a continuous record, not necessitating the sampling procedure of the open circuit system commonly used.

The second method offers a continuous digital display of corrected oxygen consumption in a totally portable unit (Oxylog). The subject wears a face mask with inspiratory and expliratory valves to which is attached a flow meter to measure inspiratory volume. Expiréd air passes through a flexible pipe connected to the instrument. The $\mathrm{PO}_{2}$ difference between the inspired and expired air is measured in the instrument and the volume of oxygen extracted from the air breathed is calculated and displayed on a counter. The prototype instrument is $8.5 \times 12 \times 20.5 \mathrm{~cm}$. in size and weighs $1.8 \mathrm{~kg}$.

The Oxylog apparatus was compared with the more traditional open circuit method of measuring oxygen consumption. The Oxylog was found comfortable for the subjects to wear even at respiratory rates in excess of $50 \mathrm{I}^{\mathrm{m}} \mathrm{min}^{-1}$, (even up to 100 l.). A nearly consistent overestimation of the oxygen consumption by $4 \%$ was found. It was accepted that standardization in respiratory volume determinations could have been a factor in such differences. The dead space seems small enough to ignore, relative to other equipment. The results were sufficiently encouraging for field trials to be undertaken and already the advantages of this system for ambulatory subjects have been appreciated. 